\title{
ANALYSES ON REGIONAL CULTIVATED LAND CHANGE BASED ON QUANTITATIVE METHOD
}

\author{
Taking Reservoir Area of Three Gorges as Example
}

Yingui Cao $^{1, *}$, Chun Yuan ${ }^{1}$, Wei Zhou ${ }^{1}$, Jing Wang ${ }^{2}$

${ }^{1}$ School of Land Science and Technology, China University of Geosciences, Beijing, P. R. China 100083

${ }^{2}$ Land Use Key laboratory, China Land Survey and Planning Institute, Beijing, P. R. China, 100035

* Corresponding author, Address: School of Land Science and Technology, China University of Geosciences, Beijing, P. R. China 100083 Tel: +86-10-82321917, Fax: +86-1082321807,Email: caoyingui1982@126.com

Abstract: Three Gorges Project is the great project in the world, which accelerates economic development in the reservoir area of Three Gorges Project. In the process of development in the reservoir area of Three Gorges Project, cultivated land has become the important resources, a lot of cultivated land has been occupied and become the constructing land. In the same time, a lot of cultivated land has been flooded because of the rising of the water level. This paper uses the cultivated land areas and social economic indicators of reservoir area of Three Gorges in 1990-2004, takes the statistic analyses and example research in order to analyze the process of cultivated land, get the driving forces of cultivated land change, find the new methods to stimulate and forecast the cultivated land areas in the future, and serve for the cultivated land protection and successive development in reservoir area of Three Gorges. The results indicate as follow, firstly, in the past 15 years, the cultivated land areas has decreased $200142 \mathrm{hm}^{2}$, the decreasing quantity per year is $13343 \mathrm{hm}^{2}$. The whole reservoir area is divided into three different areas, they are upper reaches area, belly area and lower reaches area. The trends of cultivated land change in different reservoir areas are similar to the whole reservoir area. Secondly, the curve of cultivated land areas and per capita GDP takes on the reverse $\mathrm{U}$, and the steps between the change rate of cultivated land and the change rate of GDP are different in some years, which indicates that change of cultivated land and change of GDP are decoupling, besides that, change of cultivated land is connection with the development of urbanization and the policy of returning forestry greatly. Lastly, the precision of multi-regression is

Please use the following format when citing this chapter:

Cao, Y., Yuan, C., Zhou, W. and Wang, J., 2009, in IFIP International Federation for Information Processing, Volume 293, Computer and Computing Technologies in Agriculture II, Volume 1, eds. D. Li, Z. Chunjiang, (Boston: Springer), pp. 317-327. 
lower than the BP neural network in the stimulation of cultivated land, then takes use of the BP neural network to forecast the cultivated land areas in 2005, 2010 and 2015, and the forecasting results are reasonable.

Key words: change of cultivated land; driving forces; theory of decoupling; BP neural network; Reservoir Area of Three Gorges

\section{INTRODUCTION}

Cultivated land is not only the precious natural resource and asset, but also is the important indicator for adjusting the national economy. It is significant to maintain some cultivated land at one period in one area (Jin Fengjun, 2006). Protecting cultivated land not only ensures the food production safety, but also protects eco-environment, so the quantity of cultivated land can affect the successive development in one area. There are many driving forces resulting in the cultivated land area reduction in China, such as, the policy of changing cultivated land into forestry, adjustment of agricultural structure, construction occupying the cultivated land and disasters destroying the cultivated land, at present, construction occupying has become the primary reason (Chen Baiming, 2006). The basic national situation in China is that the large population and the scarce cultivated land, which is determined that cultivated land protection and construction occupying cultivated land are contradictious all the time. At the beginning of economic construction in China, it was difficult to avoid economic construction occupying cultivated land, especially after reform and opening, the area of cultivated land decreased greatly, which aggravated the contradiction between cultivated land protection and construction occupying cultivated land gradually, the average reduction was $948.8 * 10^{3} \mathrm{hm}^{2}$ /year from 1996 to 2004, and construction occupying was $184.0^{*} 10^{3} \mathrm{hm}^{2}$ /year (Chen Baiming, 2006). Analyses the dynamic change of cultivated land and influential factors, which is helpful for using cultivated land purposely, fulfilling dynamic balance of cultivated land in one area, protecting successive development of dominant agricultural area and adjusting the relationship between cultivated land protection and economic development (Long Hualou, 2001; Bai Waiqi, 2004). 


\section{STUDY AREA}

Three Gorges Reservoir Area is the reservoir flooding areas which are affected by the returning water after the Three Gorges Dam building and the migrated and removed areas, which lies in between the coordinates of longitude $106^{\circ} 16^{\prime}-111^{\circ} 28^{\prime} \mathrm{E}$ and latitude $28^{\circ} 56^{\prime}-31^{\circ} 44^{\prime} \mathrm{N}$. The total area is $5.8^{*} 10^{4} \mathrm{~km}^{2}$ and the population is $1.7 * 10^{7}$. The primary topography is mountains, which is $74 \%$ of total reservoir areas, hills is $22 \%$ of total reservoir areas and plains and dam lands are only $4 \%$ total reservoir areas.

\section{DATUM AND METHODS}

In this paper, the social economic datum from 1990 to 2004 are from Chongqing City Yearbook, Sichuan Province Yearbook and Yichang City Yearbook. The areas of cultivated land from 1990 to 2004 are from national modifiable survey. The traditional LUCC research minds are adopted in this paper, in the same time, some new theories and methods are used. Dynamic degree of single land use is taken to analyze the change speed of cultivated land in different counties. Correlation analysis is used to find the primary factors which affect the cultivated land change. Decoupling theory and Kuznets theory are adopted to research the relationship between cultivated land areas and GDP per capita. At last, the simulation precision comparison between BP neural network and multivariate regression linear is carried out, and use the higher precision methods to forecast cultivated land area.

(1) Change ratio per year means the situation of increasing or decreasing. The formula is following (1)

$$
H=\frac{\left(U_{b}-U_{a}\right)}{U_{a}} \times 100 \%
$$

In the formula (1), $H$ represents change ratio per year, $U_{a}$ represents the area of cultivated land in the end of this year, $U_{b}$ represents the area of cultivated land in the end of last year. If $H>0$ means the area of cultivated land is decreasing, if $H<0$ means the area of cultivated land is increasing, if $H=0$ means the area of cultivated land doesn't change (Li Zhaofu, 2005).

Dynamic degree of single land use is introduced to indicate the change speed of cultivated land area in the research time (Wang Xiukan, 1998). The formula is following (2)

$$
K=\frac{\left(U_{b}-U_{a}\right)}{U_{a}} \times \frac{1}{T} \times 100 \%
$$


In the formula (2), $K$ represents the dynamic degree of cultivated land, $U_{a}$ represents the area of cultivated land in the beginning of research, $U_{b}$ represents the area of cultivated land in the end of research, $T$ represents research time.

(2) In the research of relationship between cultivated land change and some social economic factors change, the editor chooses primary factors containing urbanization ratio, capital investment, savings of people, the first production value, the second production value, the third production value and meat production.

(3) Kuznets theory expresses the relationship between economic growth and income distribution (Zhou Jie, 2004), which takes on reverse $U$ in the curve draft. Kuznets theory is introduced in this paper to illustrate the reverse U relationship between cultivated land areas and GDP per capita. Decoupling theory is introduced to analyze the relationship between cultivated land occupied and GDP growth (Chen Baiming, 2006). The experts of OECD environmental research field adopted decoupling theory to suggest the relationship between economic growth and environment pollution or indicate non-synchronism between economic growth change and environment pollution extent change. In their research process, they introduced decoupling ratio, decoupling index, absolute decoupling index and relative decoupling index (OECD, 2002). In this paper, change ratio per year of cultivated land area and change ratio per year of GDP are adopted to calculate decoupling ratio, decoupling index, absolute decoupling index and relative decoupling index. The formula is following (3)

$$
A=\left|\frac{B}{C}\right| /\left|\frac{B^{\prime}}{C^{\prime}}\right|^{D=1-A}
$$

In the formula (3), $A$ represents decoupling ratio, $B$ represents change ratio per year of cultivated land area of this year, $C$ represents change ratio per year of GDP of this year, $B$ ' represents change ratio per year of cultivated land area of last year, $C$ represents change ratio per year of GDP of last year, $D$ represents decoupling index. If $0<D \leqslant 1$ means relative decoupling index, which represents that the pressure of economic construction occupying cultivated land is little or change ratio per year of cultivated land and change ratio per year of GDP are non-synchronism. If $D \leqslant 0$ means absolute decoupling index, which represents that the pressure of economic construction occupying cultivated land is big or change ratio per year of cultivated land and change ratio per year of GDP are synchronism.

(4) In the research of cultivated land area simulation, the editor compares the precision of BP neural network and multivariate regression linear, at last the method of BP neural network is chosen in the cultivated land forecasting. 
Multivariate regression linear is the method that finds the relationship of quantitative change between two dependant variables or more dependant variables and an independent variable (Yu Jianying, 2003). Neural network is a non-linear dynamic system and has higher ability in non-linear reflection, learning and correcting, which has unique superiority in solving non-linear questions. And Back-Propagation Network is short for BP neural network, which is used widely at present and embodies the elite of neural network (Chen Wei, 2005). In this paper, three layers BP neural network is used in simulating and forecasting the cultivated land change.

\section{ANALYZE AND DISCUSS}

\subsection{Dynamic change of cultivated land area}

The formula (1) is used to calculate the change ratio per year, the result is that, the area of cultivated land takes on decreasing trend from 1990 to 2004. During 15 years, the area of cultivated land decreased by $200142 \mathrm{hm}^{2}$, the decreasing area per year was $13343 \mathrm{hm}^{2}$. From the change ratio per year, the extent of decreasing is not much, which takes on the trend, slow decreasing - dramatic decreasing - quite decreasing - dramatic decreasing - slow increasing. The years of dramatic decreasing are 1995 and 2002, and the change ratio per year are $4.77 \%$ and $9.50 \%$ respectively. The area of cultivated land is slow decreasing from 1996 to 1994, the average value of change ratio per year is $0.16 \%$, the area of cultivated land is quite decreasing from 1996 to 2001, the average value of change ratio per year is $0.97 \%$, the area of cultivated land has increasing trend from 2003 to 2004.

The formula (2) is used to calculate the dynamic degree of cultivated land and the results are divided into 5 grades. $(0,1)$ means slow increasing, $(-1$, $0)$ means slower decreasing, $(-2,-1)$ means slow decreasing, $(-3,-2)$ means quite decreasing and $(-4,-3)$ means dramatic decreasing. The dramatic decreasing areas concentrate in Jiangbei County, Banan County and Chongqing Construction area, slower decreasing areas distribute in Wanzhou County, Yunyang County, Fengjie County, Wushan County, Wuxi County, Badong County, Zigui County, Changshou County, Fengdou County, slow increasing areas distribute in Zhong County. 


\subsection{Driving forces of cultivated land change}

Change of cultivated land is the most obvious pattern that human activities affect natural resources and environment, which is controlled by the area geography environment, including climates, physiognomies and soils and so on, on the other hand, which is disturbed by human activities and people choosing the manners of cultivated land used, including population distribution, traffic situation, social requirements and economic and industrious structures (Zhao Jie, 2004; Fan Hong, 2002). The research results indicated that the change of cultivated land area is attributed to the economic development and returning forestry policy during 15 years. In this paper, the editor pays attachment to discuss the change influenced by the adjustment of industrious structures and social economic activities. Correlation analysis is used in the SPSS 11.5 (Yu Jianying, 2003), and gets the correlations between the change of cultivated land area and the changes of some social economic indicator values. The result is following Tab.1. From Tab.1, the change of cultivated land area is highly closed to some social economic indicator values, which takes on minus correlation.

$T a b$ 1. Correlation between cultivated land area and social economic indicators

\begin{tabular}{ccccccc}
\hline $\begin{array}{c}\text { Urbanization } \\
\text { ration }\end{array}$ & $\begin{array}{c}\text { Capital } \\
\text { investment }\end{array}$ & $\begin{array}{c}\text { Savings of } \\
\text { people }\end{array}$ & $\begin{array}{c}\text { First } \\
\text { production } \\
\text { value }\end{array}$ & $\begin{array}{c}\text { Second } \\
\text { production } \\
\text { value }\end{array}$ & $\begin{array}{c}\text { Third } \\
\text { production } \\
\text { value }\end{array}$ & $\begin{array}{c}\text { Meat } \\
\text { production }\end{array}$ \\
\hline $\begin{array}{c}\text { Cultivated } \\
\text { land area }\end{array}$ & $-0.96(* *)$ & $-0.97(* *)$ & -0.97 & -0.84 & -0.96 & -0.97 \\
$(* *)$ & $(* *)$ & $(* *)$ & $(* *)$ & -0.94 \\
\hline
\end{tabular}

(**) Correlation is significant at 0.01 level (2-tailed)

\subsubsection{Change of cultivated land area and economic development}

The correlation coefficients between change of cultivated land area and change of the first production vale, change of the second production value and change of the third production value are $-0.84,-0.96$ and -0.97 respectively, and the minus correlation coefficients between change of the second production value, change of the third production value and change of cultivated land area are smaller than that of between change of the first production vale and change of cultivated land area, which indicates that industrious structures have been adjusted and the values increasing of the second industry and the third industry are at the cost of the decreasing of cultivated land area. In the same time, the correlation between change of the first production vale and change of cultivated land area is minus, which demonstrates that agricultural structures are changed, and the use of cultivated land is transferred into other uses which get more production value than that of cultivated land. Using GDP per capita represents the level of economic development in order to research the quantitative relationship 
between the cultivated land area and GDP per capita. The change trait is similar as that of Kuznets curve (Cai Yinying, 2005; Zhang Zhengdong, 2005; Qu Futian, 2004), which takes on reverse U. From the trend, it reaches the peak in 1992 and descends from 1993 to 2003, which is like the part of reverse $U$. Then the curve is simulated with the statistics and the result is indicated as the equation (4)

$$
Y=\left(10^{-6}\right) * X^{3}-0.0196 * X^{2}+42.319 X+962455 \quad R^{2}=0.9519
$$

In the equation (4), $Y$ represents the area of cultivated land, $X$ represents GDP per capita, and the adjustment value $R^{2}=0.9519$. It was the construction time of Three Gorges Project from 1990 to 2004, which affects the economy of Three Gorges Reservoir Area. In the process of economic development, a lot of cultivated land was occupied by the economic construction, which brings enormous pressure to the cultivated land protection, especially in this area where the cultivated land is scarce. The editor introduces the coupling theory in order to research the industry of cultivated land to the economic development. The decoupling index between the area of cultivated land and GDP value is calculated using formula (3). The fluctuation of change trend is frequent, which demonstrates that the synchronism ratio of cultivated land area change and GDP change is unstable. Some years are absolute decoupling, these years contain 1992, 1993, 1995, 1997, 1998, 2001, 2002, which indicates that the pressure of cultivated land occupied by economic construction was small relatively. The other years were relative decoupling and the pressure of cultivated land occupied by economic construction was big.

\subsubsection{Urbanization and cultivated land change}

Urban people growing brings on the urbanization acceleration, which results in the growth of urban inhabitancy and stimulates the need of industrial land. The correlation coefficient between urbanization ratio and cultivated land area is -0.96 , which indicates that the decreasing of cultivated land area is close to the increasing of urbanization ratio.

\subsubsection{Returning forestry policy and cultivated land change}

A lot of cultivated land distribute on the hillside in Three Gorges Reservoir Area, most of them are on the hillside whose slope is bigger than $25^{\circ}$. The government appeals changing the cultivated land distributing on the hillside whose slope is bigger than $25^{\circ}$ into forestry in Three Gorges Reservoir Area. It is the important project to change those cultivated land 
into forestry, especially in the upper reach area and belly area. The policy carrying out is helpful for controlling soil losses and improving ecoenvironment, it is also useful for the agricultural adjustment and farmers income increasing. From Tab.1, cultivated land area and savings of people is minus correlation, and cultivated land area and meet production is also minus correlation, which demonstrates that the agricultural structures adjustment and farmers investment increasing are benefit from returning forestry policy. Wanzhou County, Kai County and Wulong County were made experiments for the returning forestry policy from 2000 to 2001. The area of returning forestry was $4.6^{*} 10^{4} \mathrm{hm}^{2}$ in these experimenting counties in two years. The decreasing area of cultivated land resulted from returning forestry policy was 68.08\% in 2004 (Huang Juan, 2006).

\subsection{Simulation and forecasting for the area of cultivated land}

\subsubsection{Simulation}

In the process of simulation, BP neural network and multivariate regression linear are connected and compared. In this paper, three layers BP neural network is adopted. The neural units of input layer are the values of urbanization ratio, capital investment, savings of people, the first production value, the second production value, the third production value and meat production, the neural unit of output layer is the area of cultivated land and the number of neural units of covering layer is 9. Programming in the MATLAB6.5 environment, the training goal is 0.0002 . At last, the training stops until 25824 epochs and reaches the goal. Then the areas of cultivated land of each year are simulated according to the BP neural network trained. Comparing the real values and simulating values, the editor finds that the change trend of real values and simulating values is consistent and the absolute error scale is distributing in $(-2.50 \%, 2.50 \%)$. Above all, the simulation precision is high and the simulation result is reasonable. In the same time, the multivariate regression linear is used to simulate the relationship between the area of cultivated land and the values of some social economic indicators listed above (Wu Yi, 1995). The equation of multivariate regression linear is following (5)

$$
\begin{aligned}
Y= & -240739 X_{1}-0.044 X_{2}+0.003 X_{3}-0.096 X_{4}+0.088 X_{5^{-}} \\
& 0.039 X_{6}-0.189 X_{7}+1110829
\end{aligned}
$$

In the equation (5), $Y$ represents the area of cultivated land, $X_{1}$ represents urbanization ratio, $X_{2}$ represents capital investment, $X_{3}$ represents savings of 
people, $X_{4}$ represents the first production value, $X_{5}$ represents the second production value, $X_{6}$ represents the third production value and $X_{7}$ represents meat production, and the adjusting value $R^{2}$ is 0.967 , and $F=22.261>F_{0.001}$

$(7,5)=8.10$, and meets the regression requirement. Then using equation (5) simulates the area of cultivated land of each year. At last, the absolute error between real values and simulation value is distributing in $(2.0 \%$, $21.0 \%)$.

Comparing the absolute error of two simulated methods, the editor finds the simulation precision of $\mathrm{BP}$ neural network is higher than that of multivariate regression linear.

\subsubsection{Forecasting}

Using BP neural network trained forecasts the future area of cultivated land in the MATLAB 6.5 environment programming. The forecasting years are 2005,2010 and 2015. The forecasting areas are $810500 \mathrm{hm}^{2}, 72800 \mathrm{hm}^{2}$ and $726800 \mathrm{hm}^{2}$ respectively.

\section{CONCLUSION}

(1) Change of cultivated land area takes on the rule, slow decreasingdramatic decreasing - quite decreasing — dramatic decreasing - slow increasing, and the change trend of cultivated land area per capita is similar to the total change trend of cultivated land area. The dynamic degree of cultivated land can be divided into five grades, they are slow increasing, slower decreasing, slow decreasing, quite decreasing and dramatic decreasing, and their spatial distribution are concentrated and most counties are in the state of slower decreasing. Besides, the change of cultivated land in three parts of the reservoir area is similar.

(2) Change of cultivated land area is highly closed to change of some social economic indicator values. The curve of relationship between cultivated land area and GDP per capita is similar to the Kuznets curve, which takes on reverse $U$. The synchronism ratio of cultivated land area change and GDP change is unstable, and some years were in the situation of absolute decoupling, and other were in the situation of relative decoupling, that is, the pressure of cultivated land occupied by economic construction was small relatively in some years, and others not. In the same time, urbanization and returning forestry policy resulted in decreasing of cultivated land area in fifteen years. 
(3) The absolute error of two simulated methods is compared and finds the simulation precision of BP neural network is higher than that of multivariate regression linear. Using BP neural network forecasts the future area of cultivated land and forecasting results are reasonable.

Above all, the protection of cultivated land and economic construction is contradictious, and it is significant to fulfill the policy that change cultivated land on the hillside into forestry in Three Gorges Reservoir Area. Land use planning should aim at the benefits of cultivated land protection, economic construction and eco-environment improvement.

\section{REFERENCES}

Bai Waiqi, Yan Jianzhong, Zhang Yili. Land Use/Land Cover Change and Driving Forces in the Region of Upper Reaches of the Dadu River. PROGRESS IN GEOGRAPHY. 2004, 23(1): 71-78

Cai Yinyng, Zhang Anlu. Relationships Between Cultivated Land Resource and Economic Development. CHINA POPULATION RESOURCES AND ENVIRONMENT, 2005, 15(5): $52-57$

Chen Baiming, Du Hongliang. Decoupling Research of Cultivated Land Occupied and GDP Growth. Resource Science, 2006, 26(4): 42-51

Chen Wei. Study on the Quantitative Change of the Land Demand on the Development of the Economy in Shanghai based on the Model of the BP Nerve Network. CITY MANAGEMENT AND SCIENCE, 2005, 7(2): 80-82

Fan Hong, Zhang Jianping. Study on Land Use/Cover in Arid Valley of Upper Minjiang Watershed. JOURNAL OF DESERT RESEARCH, 2002, 22(3): 273-278

Han Liqun. Theory, Design and Use of Artificial Neural Network. Beijing, 2002

Huang Juan, Diao Chengtai. Analyses of Cultivated Land Change in Recent 10 Years in Chongqing City. China Land Resources Strategy and Regional Adjustment Development. 2006, 407-411

Jin Fengjun, Zhang Xiaoping, Wang Changzheng. Land Use Problems and Intensive Utilization Patterns in the Coastal Regions of China. Resource Science, 2006, 26(5): 53-60

Li Zhaofu, Yang Guishan. Correlation Analysis between Cultivated Land Use Change and Economic Development in Suzhou City over the Past 50 Years. Resource Science, 2005, 27(4): 50-55

Long Hualou, Li Xiubin. Land Use Pattern in Transect of the Yangtse River and Its Influential Factor. ACTA GEOGRAPHICA SINICA, 2001, 56(4): 417-425

OECD. Indicators to measure decoupling of environmental pressure from economic growth. Pairs, 2002

Qu Futian, Wu Limei. Hypothesis and Validationon the Kuznets Curves of Economic Growth and Farmland Conversion. Resource Science, 2004, 26(5): 61-67

Wang Xiulan, Bao Yuhai. Study on the Methods of Land Use Dynamic Change Research. PROGRESS IN GEOGRAPHY, 1999, 18(1): 81-87

Wu Yi, Li Yongle, Hu Qingjun. Mathematics and Statistics. Changsha, 1995

YuJianyng, He Xuhong. Datum statistics analyses and SPSS application. Beijing, 2003 
Method

Zhang Zhengdong. Correlation Analysis of Cultivated Land Change with Population Increasing and Economic Growth in Hainan Province in Recent 35 Years. JOURNAL OF DESERT RESEARCH, 2005, 25(5): 273-278

Zhao Jie, Zhao Shidong, Zheng Chunhui. Study on Land Cover/Land Use Change of Naiman Banner since 1980. JOURNAL OF DESERT RESEARCH, 2004, 24(3): 317-322 